\title{
Use of Web technologies to create an information processing system of pressure metal forming processes
}

\author{
Valentin A. Osadchy ${ }^{1}$, Alexander V. Osadchy ${ }^{2}$, Valeriy V. Savin ${ }^{3}$, Lyudmila A. Savina ${ }^{3}$, Nikolai V. Novoseltcev ${ }^{3, a}$ \\ ${ }^{1}$ National University of Science and Technology MISIS, Leninskiy ave. 4, Moscow, 119049 Russia \\ ${ }^{2}$ Prokhorov General Physics Institute, Russian Academy of Sciences, ul. Vavilova 38, Moscow, 119991 Russia \\ ${ }^{3}$ Immanuel Kant Baltic Federal University, ul. Nevskogo 14, Kaliningrad, 236041 Russia
}

\begin{abstract}
The problem of obtaining reliable information when performing calculations, can be solved, thanks to the intensive development of computer facilities, using specially created databases and information systems, as well as improving data processing techniques and optimizing the characteristics of materials and products, parameters of technology and equipment. Following tasks have been solved: a) an information system in the field of metal forming and related science fields has been developed; b) a database on metal materials, metal products, technology and equipment of rolling production has been created; c) a mathematical apparatus and model of the rolling process for material and process parameters selection have been developed. Obtained as a result framework can be applied to solve a broad aspect of practical problems.
\end{abstract}

\section{Introduction}

Modern system approach to the technological processes design is based on the development of mathematical models of objects and automated search for optimal solutions. This puts on the need to change approaches to the creation and implementation of mathematical models, requires the development of complex computer systems that make modelling tasks as easy as possible. Such systems should contain information and reference materials, databases, the corresponding mathematical apparatus both general character, and for describing specific processes. In this case, they can be used not only for research purposes, but also as independent information-reference, as well as training systems.

\section{Results}

The achieved level of development and dissemination of computer equipment, as well as the accumulated baggage of mathematical methods for calculating the parameters of metal smelting and processing, allow us to begin creating a software environment for designing simulation models of processes and optimizing technological parameters, considering specific conditions and requirements with a wide use of computer information technologies in the Internet.

The use of information technologies in the development of new and improvement of existing technological processes makes it possible to fully benefit from the following opportunities:
1. Fast and complete provision of information on the problem being developed.

2. Selection of suitable calculation methods using computer analysis.

3. Search in the database for the required characteristics of materials and process parameters.

4. Construction of empirical dependencies for solving technological and research problems by statistical processing of information from the database.

5. Performing an effective comparative analysis of the results obtained at both intermediate and final stages.

6. Search for optimal process flow parameters.

The development and improvement of technological processes based on theoretical research using mathematical models is indisputably an effective way of developing production. At the same time, the successful application of mathematical models is largely determined both by the completeness of the process description and by the quality of the information used as the initial data. Further development of computational methods is required for rolling production, especially in the direction of taking account of the rolling peculiarities in calibers in determining the shape and temperature field, as well as the rheological characteristics and properties of the metal.

The problem of obtaining reliable information when performing calculations, in turn, can be solved now, thanks to the intensive development of frameworks, using specially created databases and information systems, as well as improving data processing techniques and optimizing the characteristics of materials and products, parameters of technology and equipment. Therefore, for the successful use of information technology in the

\footnotetext{
a Corresponding author: niknovo@me.com
} 
development and improvement of rolling production processes, the following tasks must be solved:

- Develop an information system in the field of metal forming with pressure and related fields of science;

- Create a database on metal materials, metal products, technology and equipment of rolling production;

- Develop a mathematical apparatus and model of the rolling process to select materials and process parameters that ensure the required level of properties.

The framework thus obtained can be applied to solve a broad aspect of practical problems.

In this paper, we present an information framework in the form of a Web application, including an information and training system, a database, programs for processing data, calculating process parameters, equipment parameters, and the characteristics of metal products.

The software package is designed for use on the Internet and designed in accordance with the currently accepted rules for organizing the interface in application systems on personal computers and any researcher or designer who does not have special skills in working with a personal computer can use it.

\subsection{Informational and training system for metallurgical production}

To facilitate the search for the required information of a descriptive nature in the field of metal working with pressure and related parts of science, an information and training computer system has been created that represents a considerable amount of information equivalent to dozens of textbooks broken down into small fragments (articles) combined with a cross-reference system (hyperlinks) and table of contents.

The structure of information storage and data access system has been developed, information on the theory, technology and equipment of metal processing processes in the press and related fields of science has been collected, processed and included in the database, which can be used as a reference in the development and improvement of technological processes, and as a computer textbook for 19 courses.

Depending on the chosen method of information access, the computer system can be used as a reference book, encyclopaedia, computer (electronic) textbook. The system is multilevel and allows you to study the problem with varying degrees of detail.

\subsection{Database on metal materials and metal products}

The database contains information on the production of ferrous and non-ferrous metals in the CIS countries. The developed structure of the database, as well as its filling and software shell, allows a quick search for information about chemical compounds and analogues of domestic and foreign non-ferrous and ferrous metals and alloys, the purpose and conditions of application, heat treatment regimes, mechanical and physical properties, the requirements of standards, technology and the characteristics of proprietary equipment available at the enterprises, etc. It is possible to obtain information about manufacturers of various types of metal products.

The main components of the database are tables, which allows you to modify the information without changing the program itself.

The software shell includes algorithms for preliminary data processing calculation of predicted values of material characteristics in the absence of required data in the database.

The database "Ferrous and non-ferrous metals" has been registered in the State Register of Databases, awarded with certificates at exhibitions, purchased and used by many Russian and foreign organizations and private individuals.

\subsection{Information and calculation system for rolling fabrication}

The correctness of the comparative evaluation of technology options is largely determined by the reliability of the data used, including technological parameters of the processes. In the CAD of rolling shops, the main component is the subsystem for the implementation of the technological part of the project, which determines the main technical solutions and the level of technical and economic indicators of the facility. It is calculations based on technological models that allow us to give an economic assessment and make a choice of technology in the future. In technological models, natural indicators of resource consumption and output are combined simultaneously. Based on such indicators, the calculation of the overall project efficiency is carried out.

Taking this into account, a mathematical model of the longitudinal rolling process has been developed for their determination, which makes it possible to determine deformation, temperature, velocity and energy parameters, and predict mechanical characteristics of the metal.

The developed mathematical model is based on engineering methods of calculation of technological parameters, provides for the possibility of process optimization, is connected to the database and information system.

Since the existing dependencies for the calculation of the most important parameters of the rolling process do not always reflect the influence of various process parameters quite adequately, and in all cases, provide sufficient reliability of the results obtained, the mathematical model provides for the choice of alternative methods.

Based on statistical processing of the results of tests of domestic and foreign ferrous and non-ferrous metals presented in the database, regression dependences of thermophysical characteristics on the temperature and the percentage content of chemical elements in steel or alloy were obtained with the help of the statistical processing program. Black and non-ferrous metals and alloys are divided into groups and equations are constructed for each of them.

To determine the deformation resistance of various deformable materials - ferrous and non-ferrous metals and alloys, they are divided into 63 groups. An algorithm 
for determining the material group and the necessary parameters for a given chemical composition of the metal has been developed. The construction of the equations considered the influence of 66 basic chemical elements in the composition of the material.

When predicting the mechanical characteristics of rolled products, an analytical approach is used in combination with the experimental one.

When entering the chemical composition of materials, determining the mechanical and thermal properties of materials, equipment parameters, databases are used.

For efficient processing of discrete data and obtaining regression dependencies in the research and modelling of technological processes of rolling, an algorithm is developed, and a program is developed that performs statistical processing of significant volumes of data, determination of correlation coefficients, and search for the best kind of functional connection.

In constructing the regression equation, all possible combinations of power terms, including negative ones, are used (logarithm, exponent) applied to individual arguments and to the whole expression.

The efficiency of solving most of problems in the development and improvement of technological processes depends to a large extent on the correctness of the postulate of the optimization problem and the quality of the applied methods of solution. In this connection, an approach and program were developed to find optimal conditions in the case of many variable parameters and a complex process model.

The search for unknown parameters is carried out by combining three numerical methods of searching for an extremum. First, a search of possible combinations of values of unknown parameters in each interval with a certain step in the parameter (scanning method) is performed. This allows in most cases to find the region of the global optimum. Then the best set of values of the required parameters is used to find the local optimum jointly by the methods of configurations and steepest descent with some additions.

\subsection{Software for assemblies and technological tools design}

In a market economy, one who survives can respond quickly to changing market needs. Recently, demand for bent rolled sections has increased substantially.

The equipment development and rolls calibration to produce bent roll profiles is a rather complicated and time-consuming task. This is due to the need to perform a large amount of calculations, from the preparation of drawings, as well as the need for optimization of calibration.

The adopted method for describing the shape of the strip and the developed method for determining the profiling route made it possible to compile a general algorithm for calculating roll calibrations in the production of bent symmetrical and asymmetric profiles of practically any real configurations such as a corner, channel, snake, trough, closed profile, etc. The program is based on a mathematical model of the strip profiling process, which allows calculating geometric and energy parameters. The developed algorithm allows to calculate the calibration of forming stands, deduce the drawings of rings and banded rolls in assembled form, includes the investigation of rational ways of profiling, in-depth analysis of situations, possibilities, numerous checks and directions of the process of flexibility at each stage production.

The main result of the program is working drawings of rollers and bandages, which can be transferred directly to production.

The program has been registered in the State Register of Databases. It is acquired and used by many Russian enterprises. With its help, calibrations of rolls have been developed and successfully used to produce all kinds of bent profiles.

Currently, work is underway to create a software for designing equipment for a roll forming mill.

Thus, a software package was created that is designed to work on the Internet and implemented in the Visual Studio environment, which made it possible to organize a convenient dialogue between a person and a computer in a dialog mode in accordance with the currently accepted rules for creating an interface in software with the use of automatically appearing forms (windows) containing input fields with explanations, buttons, menus (dropdown lists), graphs, drawings, etc. It is included in the distance learning system.

Description of the framework is available on the website [13]

Programs are provided with prompts with a tree structure with a detailed description of the methods used, explanations and recommendations for any program fragment that appear after clicking or the "Help" button on each form. The descriptions are in the form of files in HTML format using hyperlinks.

Evaluation programs include extensive diagnostics of the information to be entered to detect unrealistic values and to warn about the occurrence of errors.

\section{Summary}

The developed apparatus of computer software for the use of information technologies allows the most rational approach to improving the production processes of rolling products. The general scheme for solving practical problems with the use of the created complex includes the following main stages: search and study of information on the problem under consideration with the help of the information-learning system and literature; search for data characterizing the material and technology of its production in the database and in production; constructing regression equations from these data using a statistical processing program; execution of analysis and preliminary calculations using the mathematical model of the rolling process; search for the chemical composition and technological parameters that ensure the fulfilment of the required conditions, with the help of an optimization program, the design of tools and equipment elements. 
Previously, this approach was tested in the design of technological processes at all stages of production - from the search for the chemical composition of the metal up to the design of the technology that provides the required characteristics of the finished products.

\section{Acknowledgments}

Research was supported by Ministry of Education and Science of the Russian Federation, agreement no. 14.578.21.0252, unique project ID RFMEFI57817X0252.

\section{References}

Online references will be linked to their original source, only if possible. To enable this linking extra care should be taken when preparing reference lists.

References should be cited in the text by placing sequential numbers in brackets (for example, [1], [2, 5, 7], [8-10]). They should be numbered in the order in which they are cited. A complete reference should provide enough information to locate the article. References to printed journal articles should typically contain:

- The authors, in the form: initials of the first names followed by last name (only the first letter capitalized with full stops after the initials),

- The journal title (abbreviated),

- The volume number (bold type),

- The article number or the page numbers,

- The year of publication (in brackets).

Authors should use the forms shown in Table 3 in the final reference list.

Table 3. Font styles for a reference to a journal article.

\begin{tabular}{|c|c|}
\hline Element & Style \\
\hline Authors & $\begin{array}{c}\text { Normal } \\
\text { Initials followed by last name }\end{array}$ \\
\hline Journal title & $\begin{array}{c}\text { Normal } \\
\text { Abbreviated }\end{array}$ \\
\hline $\begin{array}{c}\text { Book title, } \\
\text { Proceedings title }\end{array}$ & Italic \\
\hline Volume number & Bold \\
\hline Page number & Normal \\
\hline Year & $\begin{array}{c}\text { Normal } \\
\text { In brackets }\end{array}$ \\
\hline
\end{tabular}

Here are some examples:

1. O.V. Sokolova, A.E. Lepestov, Forecasting the quality of welded pipe., Science and education. 6 (2011)

2. V.A. Rymov, P.I. Polukhin, I.N. Potapov, Improving the production of welded pipes (Metallurgy, Moscow, 1983)

3. B.A. Romantsev, A.V. Goncharuk, N.M. Vavilkin, S.V. Samusev, Pipe production (MISIS, Moscow, 2011)
4. V.Ya. Osadchiy, A.S. Vavilkin, V.G. Zimovets, A.P. Kolikov, Technology and equipment of pipe production (Intermet Engineering, Moscow, 2011)

5. V.N. Danchenko, A.P. Kolikov, B.A. Romantsev, S.V. Samusev, Technologies of pipe production (Intermet Engineering, Moscow, 2002)

6. S.V. Samusev, V.K. Mikhailov, E.Yu. Ivanova, V.V. Terentyev, Modern methods of calculating the calibrations of the rolls of electric-welding rigs (MISIS, Moscow, 2004)

7. Yu.M. Matveev, Theoretical foundations for the production of welded pipes (Metallurgy, Moscow, 1967)

8. S.V. Samusev, A.N. Fortunatov, Methods for calculating the stress-strain state during the production of welded pipes in the TESA line (VF MISIS, Vyksa, 2008)

9. S.V. Samusev, A.N. Fortunatov, N.A. Frolova, N.G. Pashkov, Methods for calculating instrument calibrations and energy-force parameters of the process of production of welded pipes in the press line and TESA (VF MISIS, Vyksa, 2006)

10. Yu.M. Matveev, Ya.L. Vatkin, Calibrating the tool of pipe mills (Metallurgy, Moscow, 1970)

11. A.A. Ilyushin, Continuum mechanics (Moscow University Publishing, Moscow, 1978)

12. V.I. Feodosiev, Resistance of materials: textbook for technical colleges (9th ed.) (Science, Moscow, 1986)

13. Information on http://econom.misis.ru 